\title{
Design of a DSP-Based Real-Time Control Device for Railway Vehicle Simulation
}

\author{
Yuan Yuan ${ }^{1 *}$, Wenjun Meng ${ }^{1}$ and Jisheng $\mathrm{Hu}^{2}$ \\ ${ }^{1}$ Taiyuan University of Science and Technology, 030024, China \\ ${ }^{2}$ Dalian Jiaotong University, 116028, China \\ *E-mail: yuanyuan525622@126.com
}

\begin{abstract}
A real-time control device for railway vehicle simulation is designed in this study according to the experimental requirements of a railway vehicle electric traction and electric braking system. The device uses the high-speed processing characteristic of DSP and runs on the basis of both DSP and the corresponding experimental platform. The simulation experiment for a different power grade traction system is achieved through control of the device. Full static and dynamic simulation of the operating condition of the train electric traction and braking system is attained in he case of no conmissioning.

Keywords: DSP, Traction calculation, Simulationnunning, Real-tme control
\end{abstract}

\section{Introduction}

With the acceleration of the high-speed process of Chinha's railway, the electric traction and electric braking system needs ân experimental platform that is close to the actual operation environment of the coresponding system, so that the characteristics of the product can be assessed in the research process. Generally, the static test of a development process can be completed in the laboratory whereas the dynamic test can be completed through commissioning. Hoyyever, these processes do not only involve along cycle, large workload, and high cost, but they also affect the high-speed development of railways in China [1].

To solve thi problem, a real time control device that simulates running railway vehicles and is applicable to any power and speed grade, as well as its corresponding experimental platform, is designed and developed with DSP as the core technology. This control device and the corresponding experimental platform can simulate train operation whose route and staff $10 \mathrm{ad}$ are scheduled. In the actual operation of the train, the traction motor is controlled by the torque mode, whereas in this experimental system, the actual operation of the train traction motor can be simulated through control of the torque of the tested motor. Changes in train speed can be simulated through a control of the rotating speed of the company motor. The operation condition of the electric traction and electric brakng system can be simulated by this system, including static and dynamic simulation

\section{Hardware Circuit Design of the Control System}

The entire system hardware consists of the main circuit, an industrial control computer, a TDSLF2407EA application circuit, a group of Siemens inverters, an IN338 intelligent instrument to measure the torque and rotating speed, and a set of three-phase AC asynchronous motors, as shown in Figure 1. 


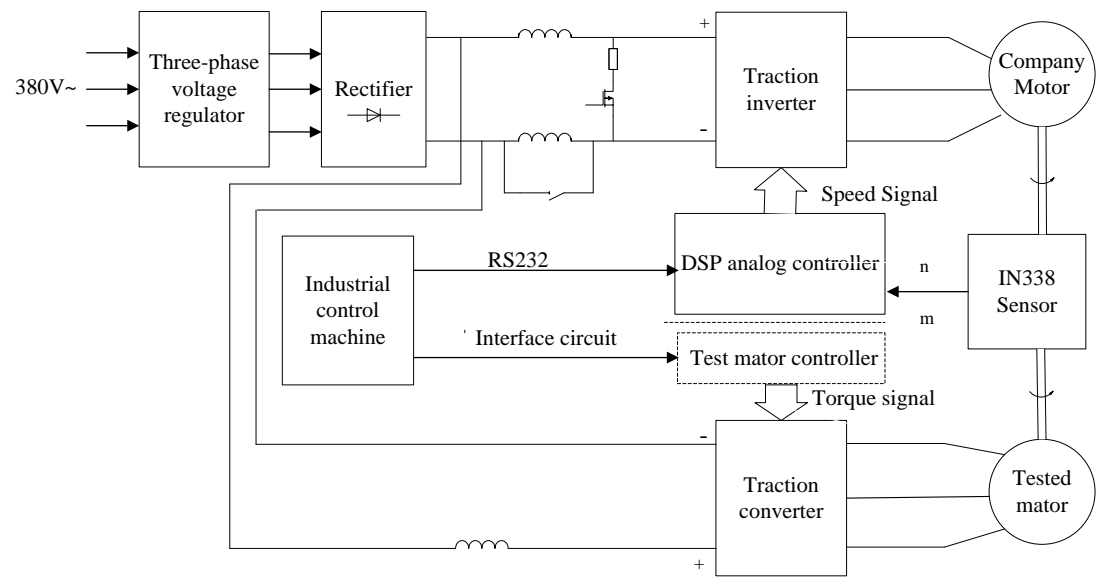

Figure 1. Block Diagram of System Hardware Structure

A three-phase voltage regulator and a three-phase full-bridge rectifier can regulate and rectify $380 \mathrm{~V}$ AC to $750 \mathrm{~V}$ DC busbar voltage. A traction inverter controls the company motor through its speed mode, whereas the traction convertor controls the tested motor through the torque mode. The industrial control computer communicates with the DSP simulation running controller via RS232. The system is initialized, including the circuit, train marshalling, and the passenger load factor, through communication with it. The IN338 torque and speed sensor obtains the torque and speed signals and forwards them to the DSP simulation running controller, which then simates these signals and outputs the results to the traction converter and lraction inverter, A speed variation in the company motor of the corresponding power leyel can be-obtamed by this closed-loop regulation.

\subsection{System Structure of the DSP Controler and the Control Mode of System} Operation

1) System structure of the DSP controller

The system structure of the DSP controller includes a power-switching circuit, DAC7625 circuit, crystal oseillation interface circuit, program memory circuit, data memory circuit, PWM drive crrcuit, communication circuit, and protection circuit, to name a few, as shown in Figure 2. 


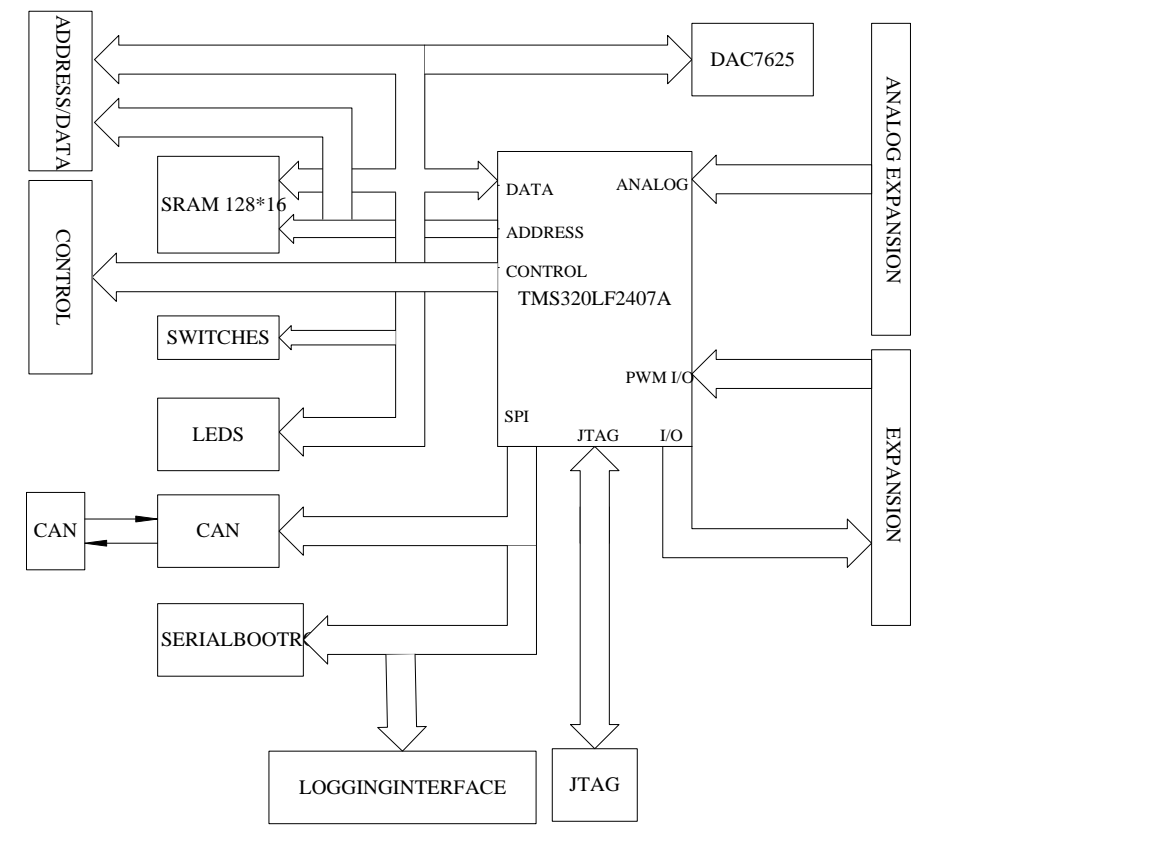

Figure 2. Logic Diagram of DSP Control Board

2) System operation mode

In this experiment, an industrial control computer an 4 a DSP simulation running controller are connected by JTAG interface during the debugging stage. The industrial control computer communicates with the DSP simulation running controller via RS232, and the DSP simulation running controller outputs the processed data in two different ways. First, the D/A conversion mogtule outputs the data to the A/D conversion module of the inverter, and second, the SCI module of the PSP outputs the data to the RS458 serial port of the inverter. Both ways use USS protocol. The DSP simulation running controller sends the signals to the thaction inyerter connected to the company motor and the converter connected to the tested motor. The company motor is controlled by speed, whereas the tested motor is controlled by the torque to achieve real-time control of the motor torque andspeed under the predetermined route, group, and passenger load factor. The system structure of the control circuit is shown in Figure 3. The system is a closedloop system and the signals lransferred to the motor group are obtained by the sensor, transferred to the DSP simulation running controller, and then passed to the motor group by the traction inverter and converter. The cycle continues until the specified line runs out, and a variation in the company motor speed is reached.

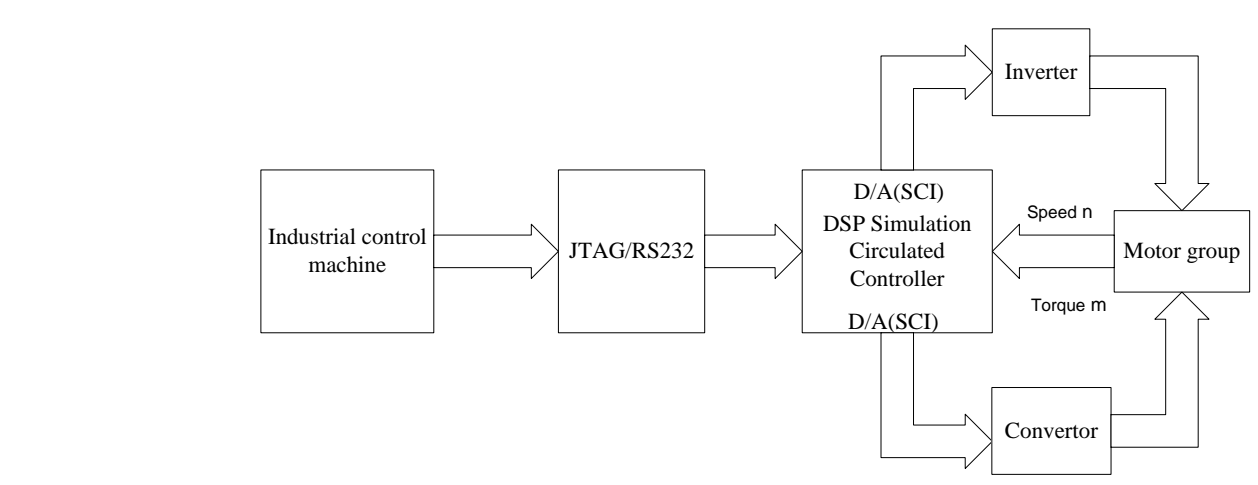

Figure 3. System Frame Chart of the Control Circuit 


\subsection{Acquisition System of the Experimental Data}

In the control system of this experiment, speed and torque signals of the motor are collected by IN338 intelligent digital sensor for measuring torque and speed. Torque and speed signals outputted by IN338 are transferred to DSP's A / D converter after optoisolator and $\mathrm{f} / \mathrm{V}$ converter, then $\mathrm{A} / \mathrm{D} 1$ and $\mathrm{A} / \mathrm{D} 2$ will complete the collection of the torque and speed signals [3-4]. As shown in Figure 4.

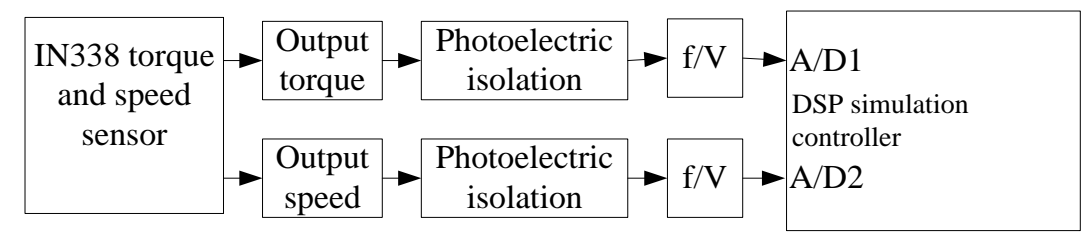

Figure 4. Hardware Chart of DSP Torque and Speed Measuring

\subsection{Design of the Signal Preprocessing Circuit}

The experiment system uses closed-loop control. After the initial speed and traction are given, the speed and torque signals processed by the DSR simulation running controller are transferred to the inverter group. The voltages of the torque signals transferred to the tested motor by the traction converter range from $10 \mathrm{~V}$ to $+10 \mathrm{~V}$ and the voltages of the speed signal transferred to the company moto $\mathrm{Dy}$ the traction inverter range from $0 \mathrm{~V}$ to $+10 \mathrm{~V}$ [5-7]. Because the reference voltage of the A/D module of TDS2407EA is 3.3V (unipolar), the voltage range of the torque and speed signals acquired by IN338 needs to be adjusted. The level conversion schenatic diagram is shown in Figure 5.

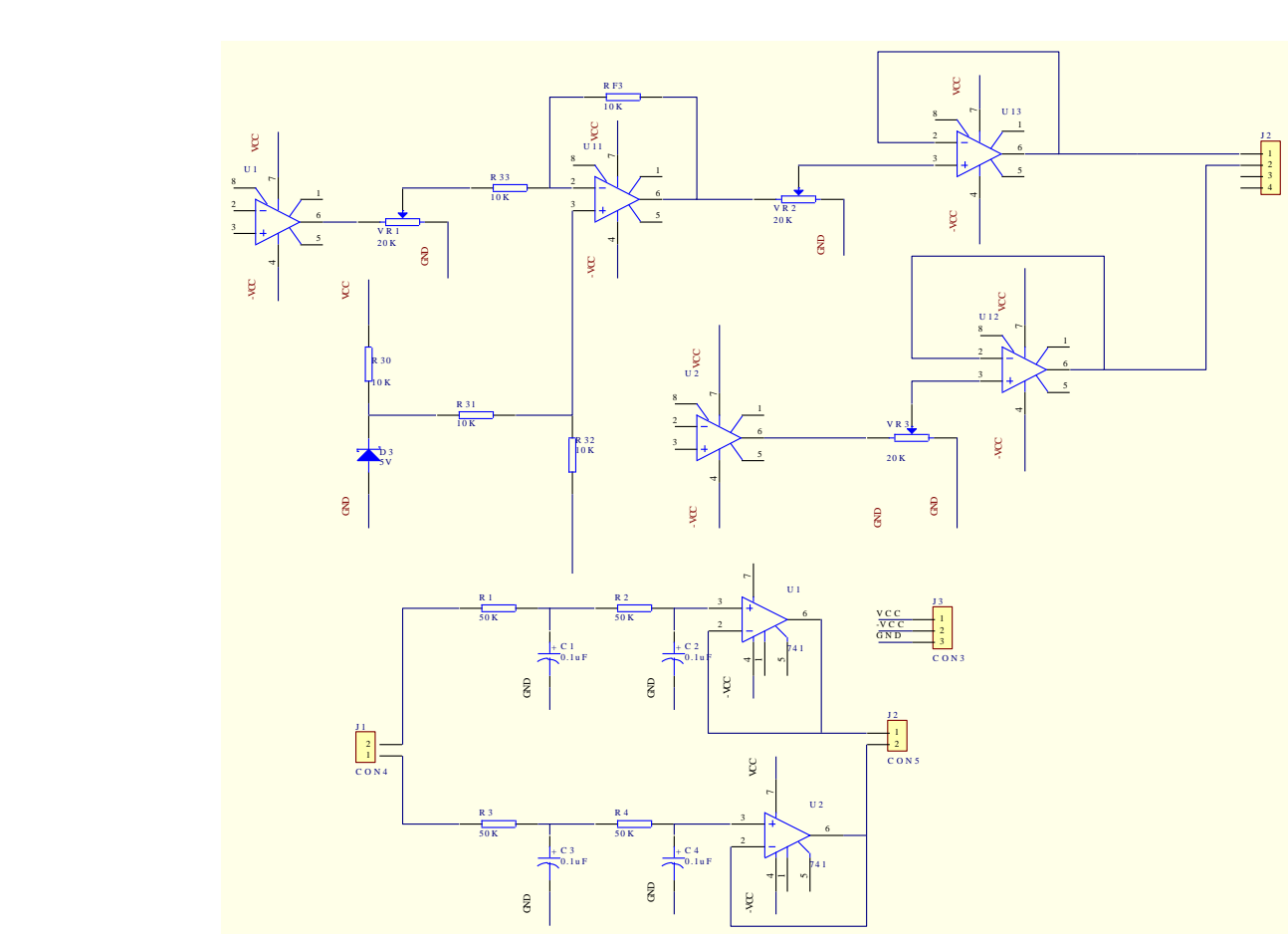

Figure 5. The Level Conversion Schematic Diagram (Input Module) 


\subsection{Design of the Output Control Circuit}

The user board of TDS2407EA is extended with D/A conversion chip DAC7625, which is 4 channeled, 12-bit double buffered, and the output is a DC voltage of $0-2.5 \mathrm{~V}$. The A/D module voltage of the traction inverter receiving the speed signal ranges from 0 to $10 \mathrm{~V}$, whereas the $\mathrm{A} / \mathrm{D}$ module voltage of the traction converter receiving the torque signal ranges from $-10 \mathrm{~V}$ to $+10 \mathrm{~V}$. The speed and torque signal circuit corresponding to the voltage are then designed, as shown in Figure 6. The circuit can transfer voltage and current. When it transfers voltage, the output voltage can be $0 \mathrm{~V}$ to $10 \mathrm{~V}$ and $-10 \mathrm{~V}$ to +10 $\mathrm{V}$; if the current needs to be transferred, the voltage-current converter chip AD694 can transfer voltage to two ways of current, which is 4-20 mA or 0-20 mA.

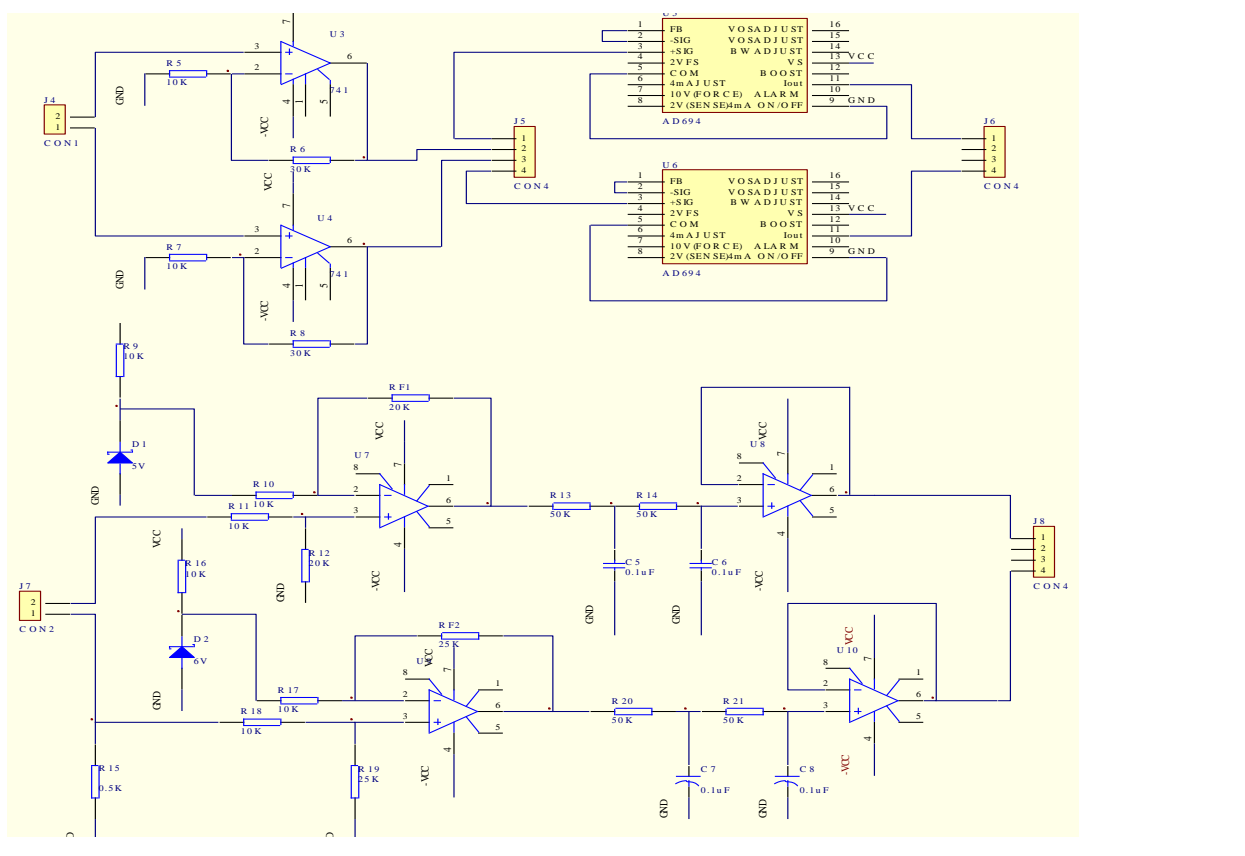

Figure 6. The Level Conversion Schematic Diagram (Output Module)

\subsection{Design of the Operating Circuit}

In this system, the operating circuit includes an analog circuit of the driver handle position and a switching circuit to simulate the conditions.

1) Design of the analog circuit of the driver handle position

In simulating the control system of railway vehicles running, the driver handle position needs to be simulated to complete the driver's set for traction and braking position and generate the required control signals. These signals will then be transferred to the traction and braking system. The function of the driver handle position is accomplished with the us - f a multiturn potentiometer to change the voltage value, so that a stepless speed or step speed regulation can be achieved, as shown in Figure 7. 


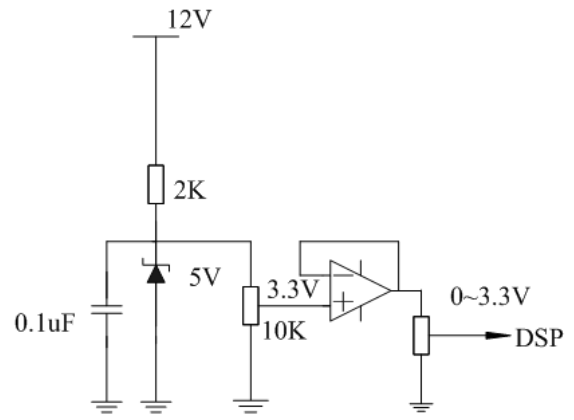

Figure 7. Handle Bit's Simulation (The Multiturn Potentiometer)

The traction and braking handle position are designed in the system, and $0-3.3 \mathrm{~V}$ is divided into eight parts. Different voltage ranges correspond to different tractiôn and braking handle positions. During the course of the experiment, the real-time control of the driver handle position for the operating condition is achieved through an adjustment of the output voltage range of the potentiometer.

2) Design of the switching circuit to simulate the operating condition

Because the DSP simulation running controller has aLED and hand witch, these are combined with the software to design the operating condition signals. If switch SW1 is pressed, light DS4, which represents the traction operating condition, will be lighted; if switch SW2 is pressed, light DS5, which represents the braking operating condition, will be lighted; if switch SW3 is pressed, light DS6, which represents the coasting operating condition, will be lighted; if switch SW4 i pressed, light DS7, which represents the stop operating condition, will be lighted. The schematic of the operating condition is shown in Figure 8.

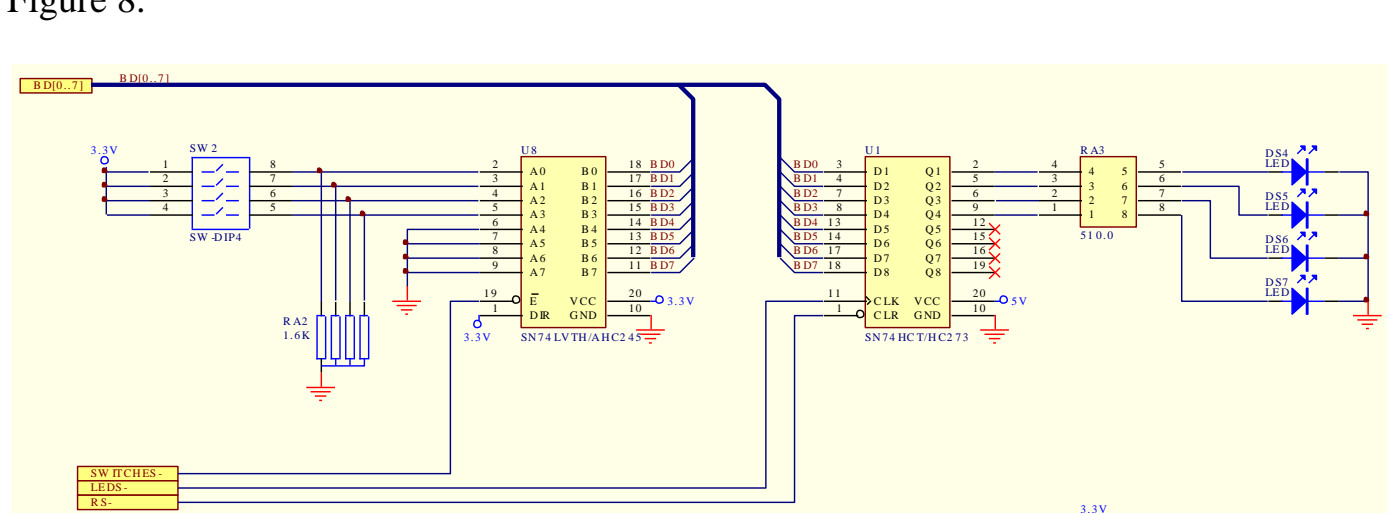

Figure 8. Schematic of Operating Condition Giving

\section{Tramsimulation Model and Algorithm}

\section{Simulation Running Model}

The train motion equation is the central link of train motion theory, the central link is to study the interrelation between traction force (or braking force), resistance and acceleration (or deceleration) so that the interrelation among train operating speed, operating distance, operating time and tractive tonnage can be find out.

When train is running on the line, there are three operating conditions: traction, coasting, braking [8-9].

If the operating condition is traction, the resultant force acting on the train is:

$$
C=F-W_{k}(N)
$$


The unit resultant force is:

$$
c=\frac{C}{(P+G) g}=f-w_{k}(N / k N)
$$

Where, $F$ is tractive effort at wheel $\operatorname{rim}(\mathrm{N}),{ }^{W_{k}}$ is the total resistance $(\mathrm{N}), P_{\text {is total }}$ weight of the train (t), $G$ is the total weight of the trailer, ${ }^{w_{k}}$ is unit total resistance, $f$ is unit tractive effort at wheel $\operatorname{rim}(\mathrm{N})$.

If the working condition is coasting, traction is zero, the resultant acting on the train is:

$$
C=-W_{k}(N)
$$

The unit resultant force is:

$$
c=\frac{C}{(P+G) g}=-w_{k}(N / k N)
$$

If the working condition is braking, the resultant acting on the train is:

$$
C=-\left(B+W_{k}\right)(N)
$$

The unit resultant force is:

$$
c=-\left(w_{k}+b\right) \quad(N / k N)
$$

Where, $B$ is train braking force $(\mathrm{N}), b$ is unit braking force $(\mathrm{N} / \mathrm{kN})$

Obviously, when $C<0$, the train will slow down, when $C>0$, the train will speed up, when $C=0$, the train will do uniform motion.

The relation among running distance, speed, time and acceleration is shown as(7)and(8).

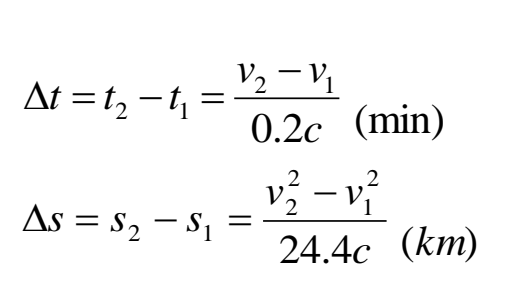

Where, $t_{1}, v_{1}$ and $S_{1}$ represent running time before a moment, running speed and running distance respectively. $t_{2}, v_{2}$ and $s_{2}$ represent the moment after simulation step $\Delta t$, running speed and running distance respectively.

\subsection{Simulation Algorith}

The algorithm used in the system simulation is a fourth-order Runge-Kutta method, and the formula

Where

$$
y\left(k_{k+1}\right) \cong y_{k+1}=y_{k}+\frac{h}{6}\left(k_{1}+2 k_{2}+2 k_{3}+k_{4}\right)
$$

$k_{1}=f\left(t_{k}, y_{k}\right) ; k_{2}=f\left(t_{k}+\frac{h}{2}, y_{k}+\frac{h}{2} k_{1}\right)$

$k_{3}=f\left(t_{k}+\frac{h}{2}, y_{k}+\frac{h}{2} k_{2}\right) ; k_{4}=f\left(t_{k}+h, y_{k}+h k_{3}\right)$

The formula consists of two parts. The first part is the result of a previous step, $y_{k}$, which is the speed of the previous moment. The second part is the weighted average of the time step $\mathrm{h}$ multiplied by the slope of the each point, which is the weighted average of the running acceleration of each point. When the initial value is known, the speed of the next moment can be determined with Formula (9). 


\subsection{Simulation Step}

When simulation step $\mathrm{h}$ is selected, ensuring the computational stability and calculation accuracy is necessary.

When the fourth-order Runge-Kutta method is used, the following empirical formula can be utilized to determine the simulation step:

$$
h \leq \frac{t_{n}}{40}
$$

Where, $t_{\mathrm{n}}$ is system transient time under the action of step function

Because the train movement is an inertial system whose time constant is large, the simulation step calculated $h \leq 10$. The simulation step is limited by a truncation error, so $h$ cannot be too large. The truncation error is proportional to the five power of $h$ to ensure that the calculation accuracy is around $0.5 \%$, which is $\mathrm{h}=0.5$.

\section{Software Design of the Control System}

System software is developed in the CCS environment which suppo ts the hybrid programming of $\mathrm{C}$ language and assembly language [10-12]. The system-software is completed by embedding assembly language in $\mathrm{C}$ language

\subsection{Design of the Main Program}

First, main program of the control system ealls the system initialization program, if runs, judge the working condition, if not, circular wait. The frame of main program is shown in Figure 9.

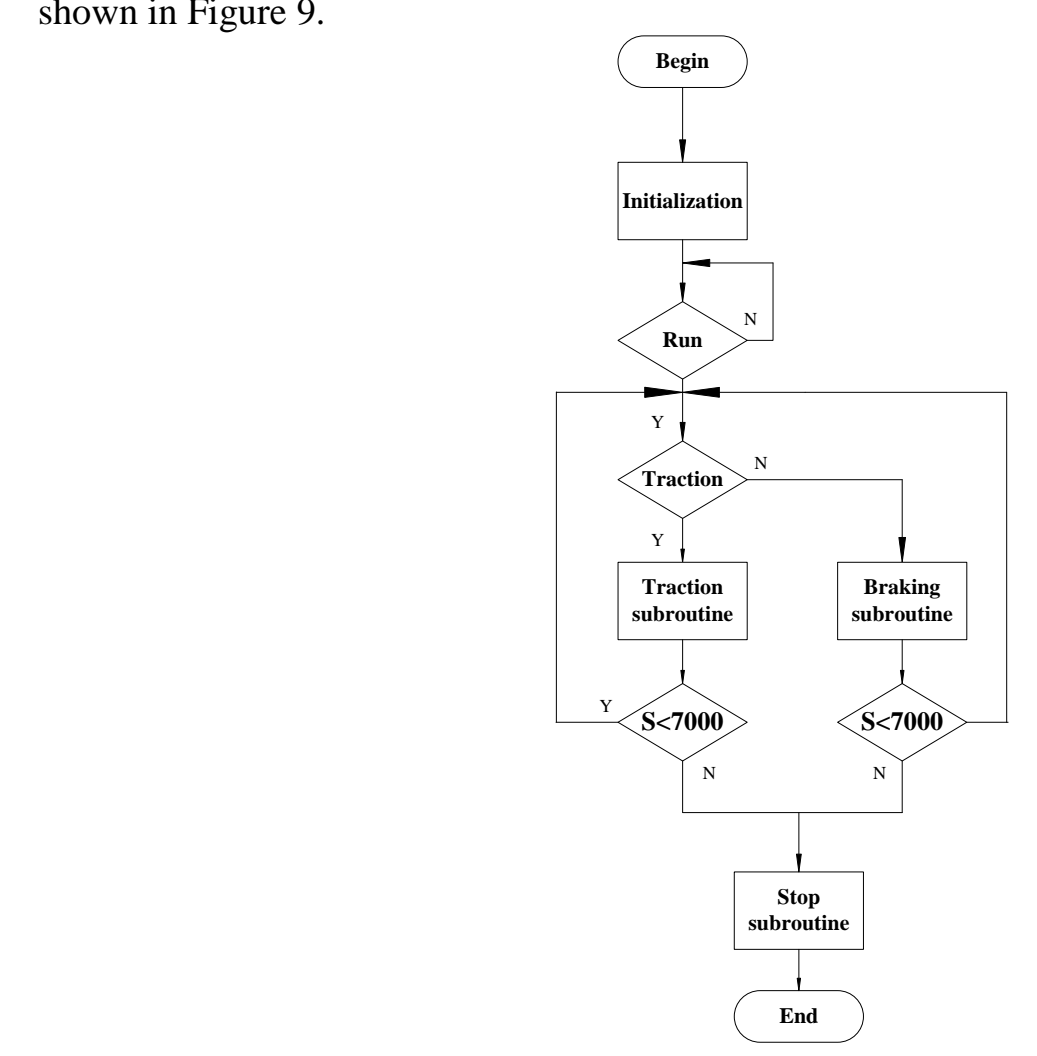

Figure 9. The Frame of Main Program 


\subsection{System Initialization}

The system needs to be initialized before the main program is executed.

System initialization consists of two parts. One is parameter initialization of the control system, which includes setting the traction (braking), number of traction motors, wheel diameter, gear ratio, transmission efficiency, speed, distance, time, and time step, among other factors. The other is initialization of the DSP simulation running controller whose function is to initialize the variable, system clock, status register, external wait, A/D module, and I/O module, among other factors, as shown in Figure 10.

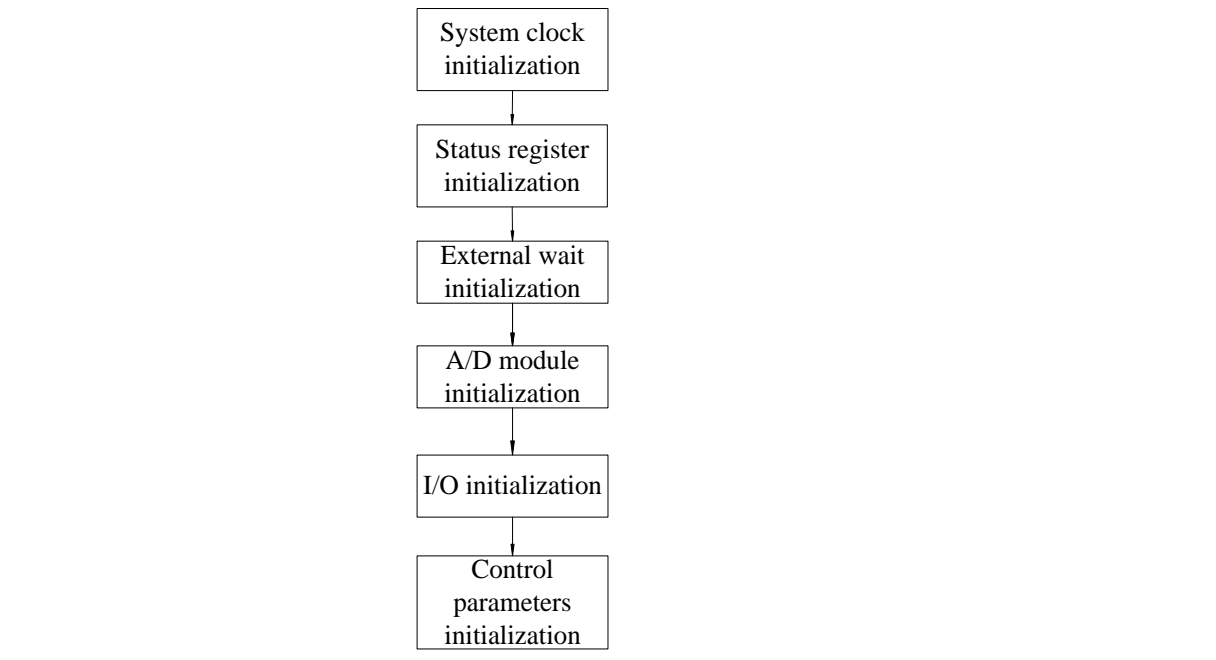

Figure 10. Flow Chart of the DSP Initialization Module

\subsection{Speed Analog Control Module}

1) Subprogram of the tested motor

At the beginning, the subprogram of the tested motor evaluates the working condition. If it is traction, the anaiog handle position and input traction characteristic curve are set. If it is braking, the braking characteristic curve is inputted, so that the torque is outputted. If it is neither, the program of the stop working condition is executed. The process is shown

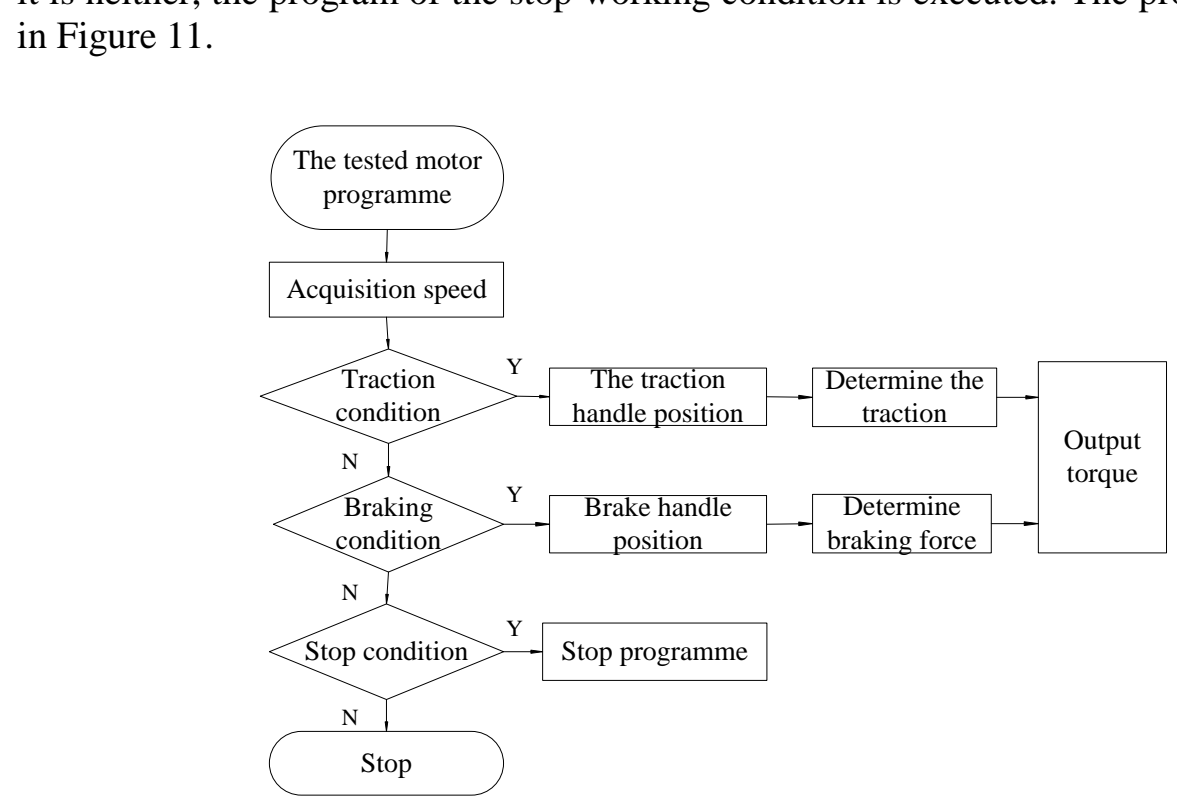

Figure 11. Subprogram Frame of the Tested Motor 
2) Subprogram of the company motor

Control program of the company motor is designed to realize the traction calculation , the program flow chart is shown as Figure 12.

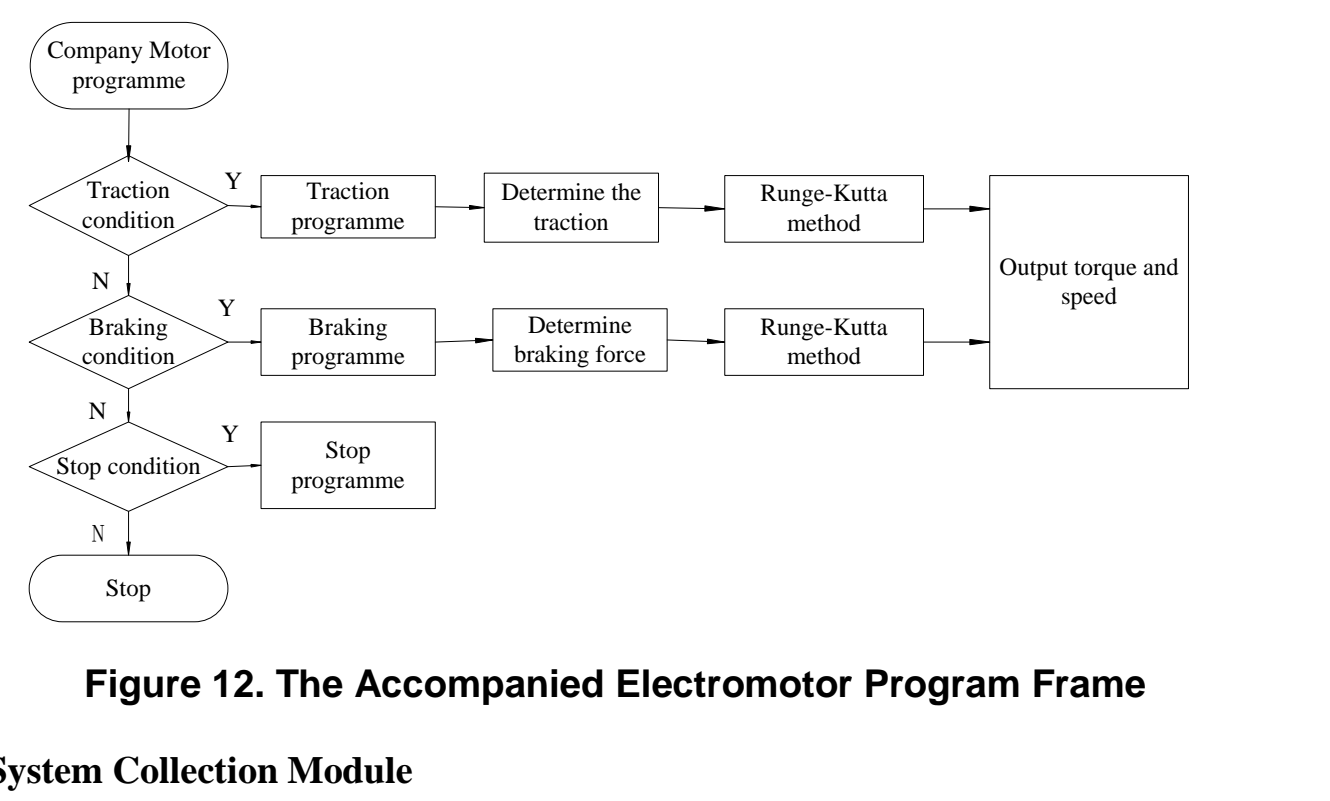

\subsection{System Collection Module}

The system obtains the speed and torque signals through the A/D module of the DSP simulation running controller in real time. The system then outputs these signals, as shown in Figure 13, after they have been processed by the controller.
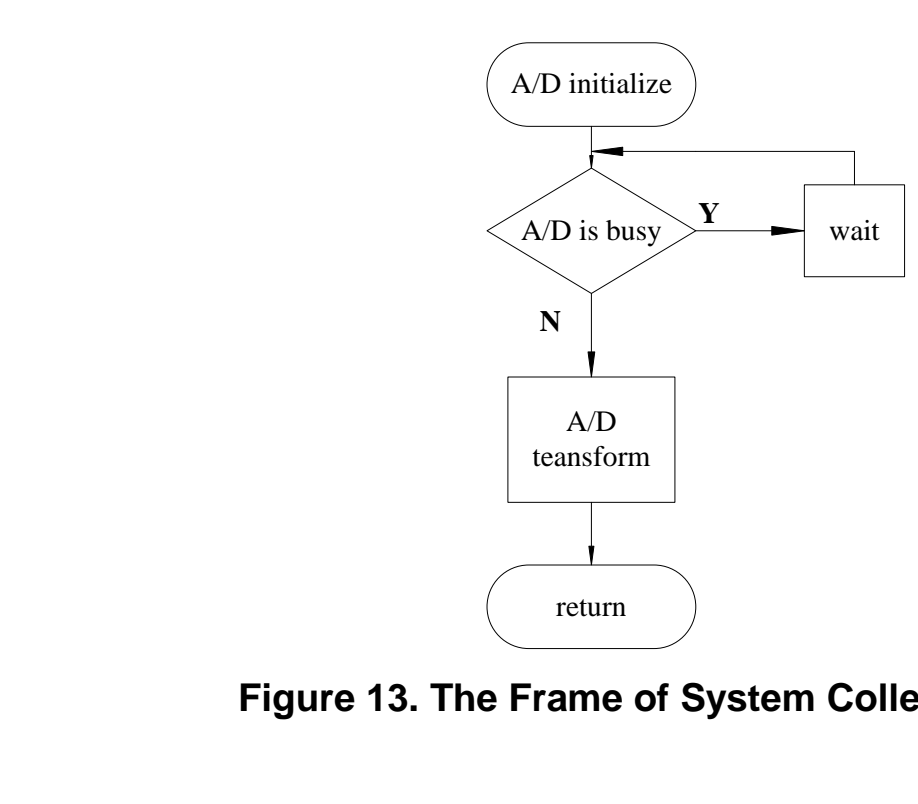

Figure 13. The Frame of System Collection Module

\subsection{Design of the System Output Module}

The system uses two methods for real-time motor control. One method involves a convertor, which has the function of D/A, to output the analog signal directly and thus control the motor; the output range is $0-2.5 \mathrm{~V}$, which is then converted to $-10 \mathrm{~V}$ to $+10 \mathrm{~V}$ to correspond to the inverter's AD reception range. The other method involves using a serial interface to output the controlled quantity with an RS232 serial interface of the analog run controller, receive the RS485 serial bus data of the motor monitoring device, and thus realize real-time control, as shown in Figure 14. 


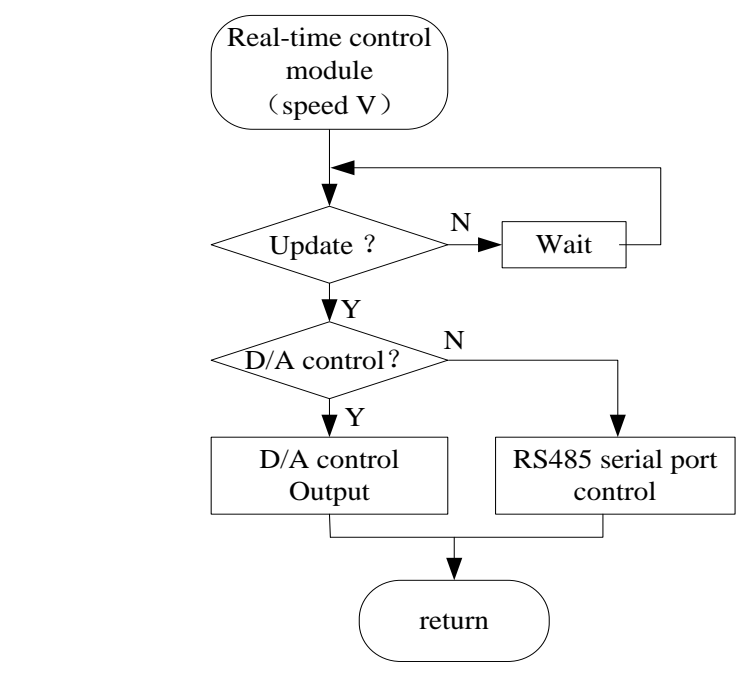

Figure 14. The Frame of System Outputt Module

\subsection{Generality and Scalability of the System Software}

The system combines hardware design and soft vare programming to simulate the train operation. With the various factors affecting train operation considered, such as changes in the operation line, traction/braking characteristics, and differences in the test motor, a modular design is used to write software. The train model, marshalling condition, and the parameters involved in the traction/braking charateristic curve can be set in the initialization process. For instance, the program used to achieve basic running resistance of the train is shown as follows

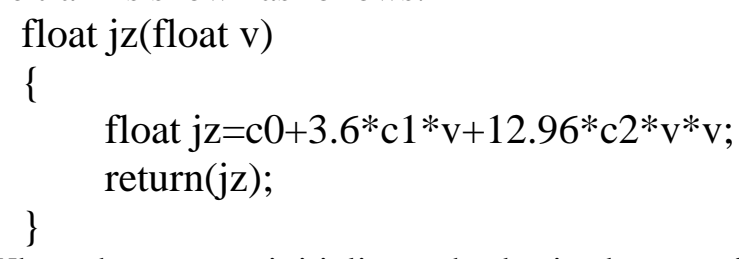

When the system initializes, the basic drag coefficients $\mathrm{c} 0$, $\mathrm{c} 1$, and $\mathrm{c} 2$ are initialized through serial port communication between the industrial control computer and the DSP simulation ruming confroller. When changes in the system working environment cause the basic drag coefficient lo change, we only need to attach the changed values to $\mathrm{c} 0, \mathrm{c} 1$, and $\mathrm{c} 2$. These different parameters ensure that the device is applicable to the real-time operation of thê train in different power levels and groups.

\section{Experimental Process and Results}

In Order to achieve the train simulation running, you need to set scheduled route, scheduled load factor, marshalling condition and the driver handle position etc. The circuit diagram is shown as Figure 15. 


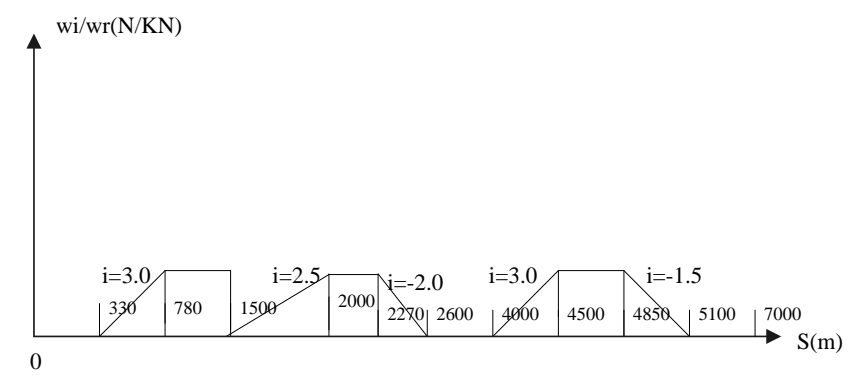

Figure 15. The Circuit Diagram

With the rated power( $15 \mathrm{~kW})$, wheel diameter $(1000 \mathrm{~mm})$, and transmission ratio $(0.98)$ of the tested motor in the experiment, the traction curve corresponding to the max traction handle position and the braking curve corresponding to the max braking handle position can be determined. The middle handle position is calculated with the interpolation method.

In the simulation process, some space is opened up in the data storage unit of DSP to store the speed value in real time. Post experiment, the speed curve of the train can be obtained after Matlab processing. This curve is outputted when the traction motor power is $15 \mathrm{~kW}$, the rated speed is $1176 \mathrm{r} / \mathrm{min}$, the motor car weight is $11 \mathrm{t}$, the trailer weight is $9 \mathrm{t}$, the passenger load factor is $50 \%$, and the train runs at max traction and braking handle position. The speed curve is shown as Figure 16, and the traction and braking curve is shown as Figure 17.

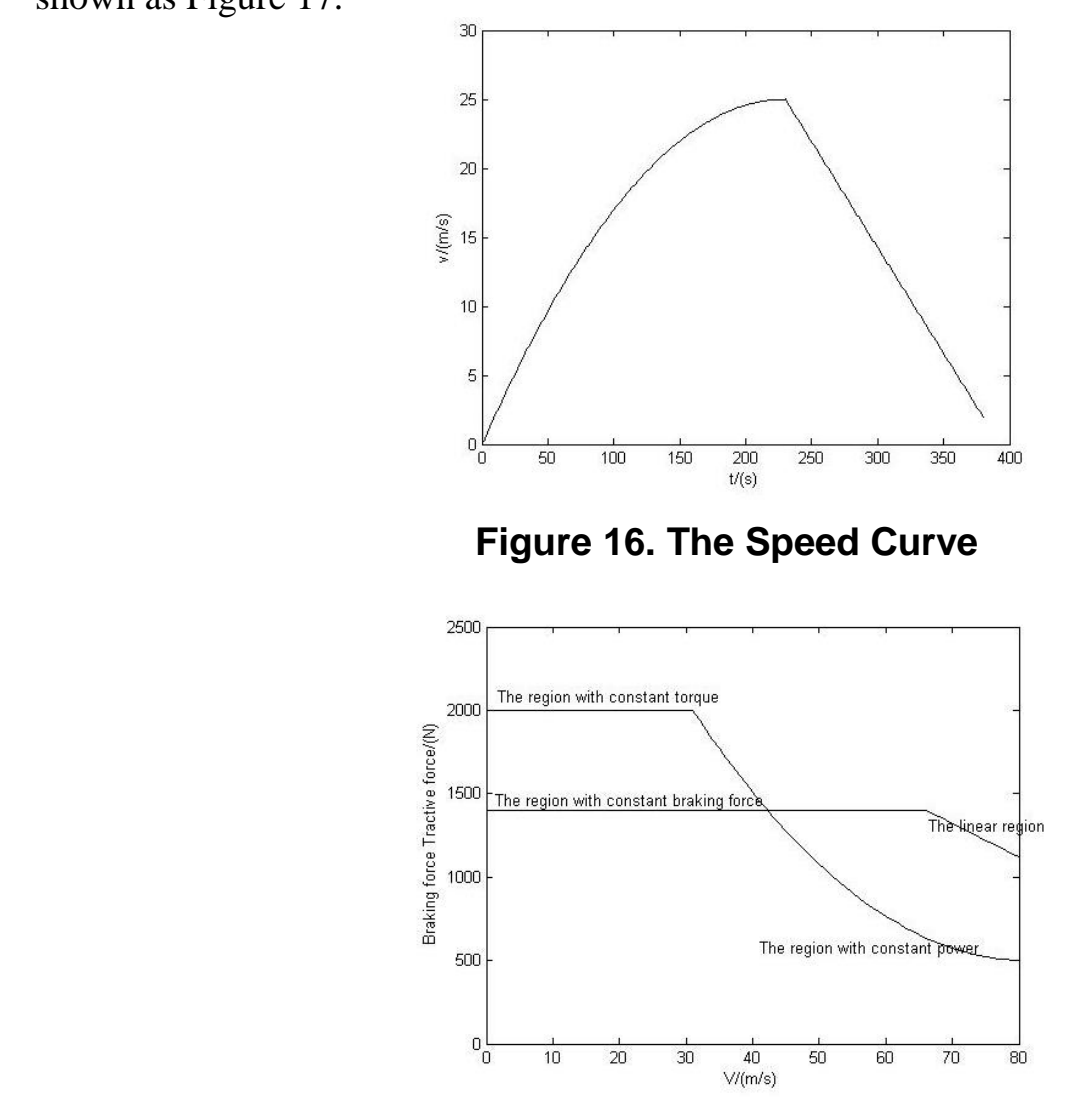

Figure 17. The Traction and Braking Curve 


\section{Conclusion}

A real-time control device is developed to simulate the operation of a railway vehicle. This device can be applied to a traction system that has different power levels. The experiment uses a motor group whose power level is $550 \mathrm{~V} / 15 \mathrm{kw}$ to complete the dynamic simulation of the running train and verify the reliability of the device. The application described in this study works well during the experiment, and the set goal is achieved.

\section{Acknowledgments}

The project is subsidized by The National Natural Science Foundation of China 51075289; The National Natural Science Foundation International (Areas) Cooperation and Exchanges Project 51110105011; The Natural Science Foundation of 2014011020-2; Shanxi Science and Technology Development Plan 2014 (Industrial) Project 20140321008-04; Shanxi Province Graduate Excellent Innovation Project Fund under Grant No. 20133116.

\section{References}

[1] S. R. Gang, Y. Jian and H. H. Ming, "Experimental Urban Rail Vehicle Traction System", Railway Vehicles, vol. 10, (2008), pp. 28-31.

[2] M. Rodic, K. Jezernik and M. TrleP, "Control Design in Mechatronic Systems Using Dynamic Emulation of Mechanical Loads", Proceedings of IEEE International Symposium on Industrial Electronics, Croatia, (2005), pp. 1635-1640.

[3] M. Chen and L. Min, "JN338 intelligent digital torque speed sensor and its application", International Electronic Elements, vol. 11, (2003), pp. 56-58.

[4] Texas Instruments Incorporated, Editor, "CPU and peripheral of TMS320LF240xDSP", Tsinghua University Press, Bei Jing, (2008).

[5] J. S. Min, "TMS320LF240xDSP hardware development course", China Machine Press, Beijing, (2007).

[6] W. X. Ping, "Principle and application design of switch power", Post \&Telecom Press, Beijing, (2012).

[7] L. S. Jie, L. Feng and Y. Z. Ping, "Torque Controlin Traction Motor Load Simulation System", Electric drive, vol. 12, (2010), pp. 52-60.

[8] C. Cole, "Handbook of Railway vehicle Dynamics", Australia: Taylor \& Francis Group, LLC, (2006).

[9] X. T. Yuan and F. W. Hui "The modeling and simulation of continuous system", Publishing house of electronics industry, Beijing, (2012).

[10] W. L. Gang and C. . Kang, "DSP C2000 master advanced programmer", China Machine Press, Beijing, (2005).

[11] Texas Instruments Incorporated, Bditor, "TMS320LF series DSP instructions and programming tools", Tsinghua Uni ersity Press, Berjing, (2005).

[12] T. H. Qiang. "The fourth edition of C programming", Tsinghua University Press, Beijing, (2010).

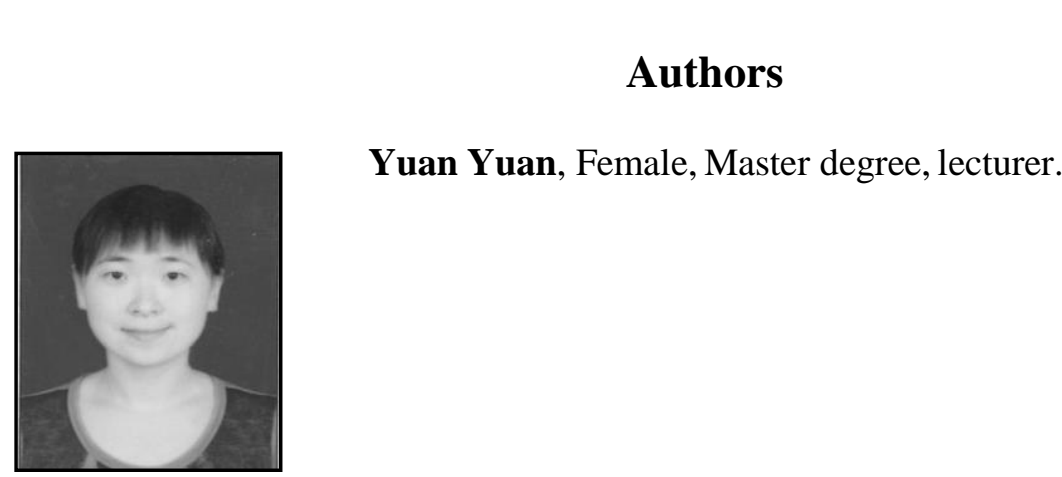


International Journal of Multimedia and Ubiquitous Engineering

Vol.11, No.10 (2016)

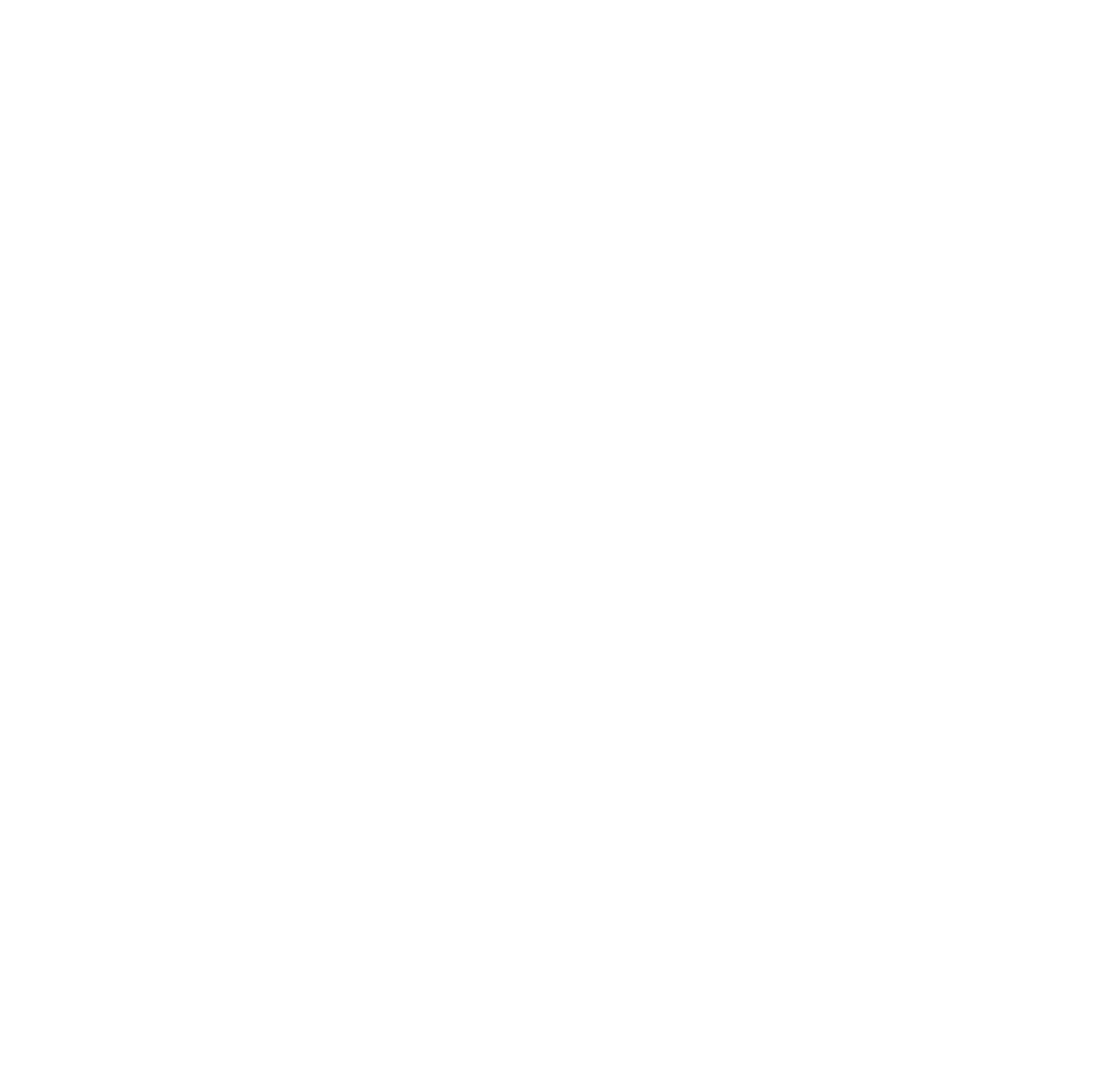

